\title{
Research on the Relationship between R \& D Investment and Corporate Value of "Unicorn" Companies: Based on the Financial Flexibility of Artificial Intelligence Company Data
}

\author{
Yang Lu1, Qingjun Meng1, Yan Cai' \\ ${ }^{1}$ Department of Finance, Business School of Hohai University, Nanjing, China \\ ${ }^{2}$ Department of Accounting, Business School of Hohai University, Nanjing, China \\ Email: 451172516@qq.com
}

How to cite this paper: Lu, Y., Meng, Q.J. and Cai, Y. (2018) Research on the Relationship between R \& D Investment and Corporate Value of "Unicorn" Companies: Based on the Financial Flexibility of Artificial Intelligence Company Data. Open Journal of Business and Management, 6 , 953-962.

https://doi.org/10.4236/ojbm.2018.64070

Received: August 11, 2018

Accepted: October 26, 2018

Published: October 29, 2018

Copyright $(9) 2018$ by authors and Scientific Research Publishing Inc. This work is licensed under the Creative Commons Attribution International License (CC BY 4.0).

http://creativecommons.org/licenses/by/4.0/

\begin{abstract}
In the modern era, the artificial intelligence industry has promoted the development of the economy with its own rapid development. Among them, financial management occupies a pivotal and indispensable position, especially the artificial intelligence industry in the "unicorn" corporate category. It relays on R \& D investment, but there are still many uncertain factors in the capital operation process, such as capital structure, investment and risk management. All have greater uncertainty and risk which makes the requirements for the flexible use of financial management more stringent. It is necessary to look for a long-term perspective strategy suitable for the development of the company. Based on this background, this article proposes some existing problems in the current $\mathrm{R} \& \mathrm{D}$ investment from the perspective of financial flexibility and how to apply the advantages of financial flexibility reasonably to solve problems and achieve rapid development [1].
\end{abstract}

\section{Keywords}

"Unicorn" Company, R \& D Investment, Artificial Intelligence,

Technological Innovation, Financial Flexibility, Financing Model

\section{Introduction}

Since the famous American investor Aileen Lee named the startup with a valuation of over one billion US dollars in private and open markets as "Unicorn" in 2013, the term "Unicorn" has rapidly become popular in Silicon Valley [2]. The globalization of innovation and socialization in the new economic era have promoted the 
accelerated flow of resources and created the basic conditions for the emergence of a large number of "Unicorns". From Yahoo to Google, Facebook and so on, many cases of "Unicorn" companies have demonstrated that they play a pivotal role in industrial transformation, and economic development. Industry innovation may lead to the promotion and development of industry's new business.

During the "13th Five-Year Plan" period, China must speed up the cultivation of regional innovation and entrepreneurial ecology, which will inevitably lead to the emergence of a large number of "Unicorns" from the fields of science and technology, the Internet and the future in intelligent hardware and big data. There may be a centralized outbreak of applications and artificial intelligence. As a category of "Unicorn" companies, the future development of artificial intelligence companies has also aroused the attention of our country. Meng Wei stated that in 2018, we will take stronger measures to implement the strategic emerging industries development plan in "13th Five-Year". Accelerate the deep integration of the Internet, big data, artificial intelligence and the real economy. We will continue to promote "Made in China 2025", introduce "Internet+" policy documents supporting the economic development of the entity, implement artificial intelligence innovation and development projects, and accelerate the digital transformation of industries, agriculture, and services.

However, there are only a handful of start-up companies that can become "Unicorns" in the tech industry because the chance of becoming a "Unicorn" is less than 1\%. From 2003 to 2013, only 39 companies achieved a target of \$1 billion in valuation in more than 60000 companies. It can be seen that the artificial intelligence companies generally face such a problem: excessively high R \& D investment makes the company bear high cost and risk, so most of them will eventually fail due to insufficient R \& D investment or improper use of funds. How to reduce costs as much as possible, make full use of $\mathrm{R} \& \mathrm{D}$ investment, and maximize the benefits of the company?

\section{View the Relationship between R \& D Investment and Corporate Value from the Perspective of Financial Flexibility}

Based on the perspective of financial management, the concept of financial flexibility was proposed-the ability of maximizing the value of the company with a reasonable price, obtaining and mobilizing financial resources in time to prevent and use uncertain events may happen in the future. Maintaining financial flexibility is a kind of self-protection measures for companies to deal with environmental uncertainties. Therefore, we consider the relationship between R \& D investment and corporate value from the perspective of financial flexibility, use financial decisions to make use of the financial flexibility.

The existing research mainly analyzes the role of financial flexibility from national related policies, capital structure and financing methods. Among them, Yang Hao and Wang Peng (2015) sampled the companies listed on China's 
ChiNext Board found that financial subsidies have a positive effect on business performance, but the financial allocation and $\mathrm{R} \& \mathrm{D}$ efficiency still need to be improved; Zong Qingqing (2015) indicate that R \& D investment of enterprises is affected by regional financial science and technology support, venture capital investment, intellectual property protection and cultural environment from external factors. Chen Jing, Pan Haiying (2017) found that there may be a non-linear relationship between capital structure and corporate value through empirical analysis, this relationship may be affected by the level of cash holding [3]; Dong Li and Mao Ning (2013) studied the impact mechanism of the company's cash dividend payment life cycle characteristics because of the ability of residual liabilities. Using the data of China's listed companies from 2005 to 2011, conducted an empirical test and found that the cash dividend payment and the company's maturity are generally positively related to the conclusion [4]; Du Xiaorong, Chen Jun, Xie Xu (2017) pointed out that commercial credit is positively related to corporate growth. That is to say, the higher the proportion of commercial credit, the better corporate growth [5].

\section{Cases and Research Methods}

\subsection{Selected Samples and Research Methods}

There are 59 artificial intelligence companies listed on the market in China and 10 of them are leading companies, including KTC, Chuanda Dazhisheng, Hanwang Technology, and Wanxun Automation. Combining existing studies and their 2016 financial results, we use the methods of the key index selection and historical data comparison after collecting relevant data. We analyze the relevant data and mainly use the following indicators as the analysis basis to discuss the relationship between $\mathrm{R} \& \mathrm{D}$ investment and corporate value:

1) R \& D intensity ( $\&$ \& D input/operating income);

2) Technical staff ratio (technical staff/employees);

3) Indicators for $R \& D$ of unit assets ( $\&$ \& input/total assets).

The $\mathrm{R} \& \mathrm{D}$ intensity is the main indicator, and the rest are used as reference indicators to fully understand the impact of the R \& D investment of the company on the overall operations.

\subsection{Research Results}

1) Analysis of R \& $D$ Investment

It's not difficult for us to draw some conclusions from research and development status of leading stocks in the artificial intelligence industry in Table 1. Throughout the led a rally in shares of the a-share market in recent years, the company's R \& D intensity is much higher than the average level, which is particularly evident in the growing artificial intelligence stocks, such as Kedaxunfei, hanwang technology, Sichuanzhisheng industries leading shares, their R \& D spending to operating income ratio ( $\mathrm{R} \& \mathrm{D}$ intensity) are more than $10 \%$.

In addition to the individual exceptions, we can conclude that the company's 
$\mathrm{R} \& \mathrm{D}$ unit and R \& D intensity are positively related, weighted average net assets profit margins are positively related to the intensity of $\mathrm{R} \& \mathrm{D}$ from the overall situation of those chosen artificial intelligence company on the behalf, artificial intelligence, visible R \& D for artificial intelligence company R \& D strength more closely and further relates to the overall profitability of the company.

2) The Relationship between R \& D Intensity and Company Earnings

It can be seen from the above analysis of relevant data of industry leaders that there is a certain relationship between $\mathrm{R} \& \mathrm{D}$ investment and the growth of listed companies' performance; companies with high $\mathrm{R} \& \mathrm{D}$ investment will have higher returns.

A fact can be concluded from the statistics in Table 2 that the research and development intensity of science and technology (UST), which has the highest R \& D intensity in the past six years, has maintained at least $20 \%$ and the proportion of technical personnel has been increasing year by year, stable at over $60 \%$, which can be said to be the leading position in the same industry [6].

Among them the weighted average return on equity of the company also has a significant positive correlation with $\mathrm{R} \& \mathrm{D}$ intensity. The weighted average

Table 1. Research and development status of leading stocks in the artificial intelligence industry (2016).

\begin{tabular}{ccccc}
\hline Company Name & $\begin{array}{c}\text { R \& D } \\
\text { Intensity }\end{array}$ & $\begin{array}{c}\text { Technical Personnel } \\
\text { Proportion }\end{array}$ & $\begin{array}{c}\text { Unit R \& D } \\
\text { Investment }\end{array}$ & $\begin{array}{c}\text { Weighted Average Net } \\
\text { Asset Profit Margin }\end{array}$ \\
HkustXunfei & $21.36 \%$ & $61.92 \%$ & $6.81 \%$ & $7.50 \%$ \\
Sichuan zhisheng & $17.62 \%$ & $61.05 \%$ & $3.67 \%$ & $3.04 \%$ \\
Hanwang technology & $13.47 \%$ & $30.00 \%$ & $5.96 \%$ & $2.83 \%$ \\
emerging & $8.56 \%$ & $25.08 \%$ & $2.32 \%$ & $8.80 \%$ \\
Wanxunself-control & $7.49 \%$ & $19.97 \%$ & $3.58 \%$ & $3.80 \%$ \\
Unisplendour & $6.44 \%$ & $39.21 \%$ & $4.81 \%$ & $4.90 \%$ \\
Hkust intelligent & $6.24 \%$ & $43.76 \%$ & $2.22 \%$ & $11.17 \%$ \\
He Er Tai & $5.77 \%$ & $11.03 \%$ & $4.86 \%$ & $11.62 \%$ \\
Jiadu Technology & $4.10 \%$ & $18.54 \%$ & $2.37 \%$ & $4.36 \%$ \\
Saiwei intelligent & $4.06 \%$ & $25.13 \%$ & $1.96 \%$ & $12.79 \%$ \\
\hline
\end{tabular}

Table 2. Research and development status of Xunfei from 2011 to 2016.

\begin{tabular}{cccc}
\hline Annual & R \& D Intensity & Technical Staff Proportion & Weighted Average ROE \\
\hline 2016 & $21.36 \%$ & $61.92 \%$ & $7.50 \%$ \\
2015 & $23.08 \%$ & $67.00 \%$ & $9.17 \%$ \\
2014 & $29.18 \%$ & $65.70 \%$ & $10.79 \%$ \\
2013 & $29.24 \%$ & $60.60 \%$ & $10.63 \%$ \\
2012 & $28.87 \%$ & $59.80 \%$ & $14.64 \%$ \\
2011 & $26.63 \%$ & $59.20 \%$ & $13.57 \%$ \\
\hline
\end{tabular}


return on net assets is used as a dynamic indicator to emphasize the profit earned by net assets during the period of operation. It is used to explain the size of the company's ability to use the net assets of a company to create profits, which is helpful to analyze the future profitability of the company.

It can be seen that high $\mathrm{R} \& \mathrm{D}$ intensity will help improve the company's scientific research capabilities, further enhance the company's competitiveness in technological innovation and have higher profitability. Existing research shows that there may be a certain positive relationship between $\mathrm{R} \& \mathrm{D}$ investment and corporate value which will be slightly different under the adjustment of financial flexibility.

From the perspective of financial flexibility, corporate $\mathrm{R} \& \mathrm{D}$ investment is influenced by both internal and external factors, financial flexibility can positively regulate $\mathrm{R} \& \mathrm{D}$ investment and corporate performance and different financial flexibility policies can produce different effects on R \& D investment [7]. Therefore, science and technology enterprises actively promote financial flexibility to meet the dynamic needs of $\mathrm{R} \& \mathrm{D}$ investment have a great practical significance, which helps to make full use of the advantages of financial flexibility in terms of financing, capital utilization, and income distribution.

However, the current research on financial flexibility in China has just started. There is a lack of research on financial flexibility-related issues in the context of China's special system. So it is necessary to analyze the problems in the R \& D investment of companies from the perspective of financial flexibility and combine existing research results to consider related solutions.

\section{The Analysis of the Problems in the Analysis of R \& D Investment from the Perspective of Financial Flexibility}

Through the relevant data in the annual reports in each company combined with the own patented inventions and other resources of companies and financial environment, making horizontal comparison of several high-level companies in the industry and vertical comparison from 2011-2016. Found the characteristics on these companies have a better market performance and concluded that there are some problems in the use of financial flexibility in the overall industry of the artificial intelligence company in China.

\subsection{Insufficient Investment in R \& D, Difficulties in Product Realization and Expansion of Bubble Phenomenon}

The artificial intelligence industry depends on scientific and technological innovation, and product replacement is fast. If $\mathrm{R} \& \mathrm{D}$ investment is insufficient, scientific research strength is weak and innovation capacity is insufficient, it will lead to difficulty in achieving product landing targets. From a technical point of view, China has a huge database and does not lag behind in application algorithms; there is only a serious flaw in the area of computational power. The deficiencies in the technological field of chips in China extend to artificial intelli- 
gence chips, thus the technological development of some parts of enterprises still needs a certain process. The industry has a high technical threshold and requires a long period of investment. Many entrepreneurial R \& D companies cannot implement the products in the short term and with the situation of the large number of competitors which leads to the overheated startup and investment. With the emergence of "pseudo-concepts", the potential bubble in the market has expanded and it is difficult for enterprises to seize market share. The application and development prospects are not optimistic.

\subsection{High Industry Risks, Financing Difficult with High Costs}

There are many innovations in artificial intelligence companies, but few products are actually available for clinical use. Immature technology will not be able to produce unqualified products, it will be difficult to achieve stable growth, and it lacks the ability to compete with giants. In addition, the current investment demand is large and the supply of entrepreneurial projects is reduced. The market expectation is high and the product experience is poor [8]. These conditions mean that companies entering the industry must take great risks.

At the same time, large risks will make the company's credit rating lower which lead to the phenomenon such as financing difficulties, higher capital acquisition costs and capital shortages. In 2017, many companies in the field of drones have encountered problems in their funds. For example, billions of airlines and zero layoffs have been drastically reduced. A large number of artificial intelligence companies have failed due to lack of commercial application capabilities. How to raise funds is a major issue to be solved in the future development of artificial intelligence companies.

\subsection{The Too High or Too Low Degree of Dispersion of Shares Can Harm the Interests of the Company}

When the artificial intelligence company's equity is more concentrated, the behavior of its controlling shareholders depends on the proportion of shares held. When the shareholding ratio is low, the controlling shareholder will not take into account the common interests of the parties involved in the parties, so it is easy to infringe on the interests of small and medium shareholders to meet their own private interests; when the shareholding ratio is at a relatively high level, major shareholders will consider your own interests are closely linked to the interests of the company [9]. Therefore, you will pay attention to the company's earnings and reduce the harm to the interests of small and medium shareholders.

However, if the equity is dispersed, with the increase in the number of shareholders, the controlling shareholder has to consider the problem of easy loss of control. Therefore, for the purpose of reducing the possibility of unlawful embezzlement of corporate assets by management, it will reduce the company's cash reserves and does not tend to distribute. Dividends can easily lead to internal conflicts. 


\section{Research Conclusions and Recommendations}

In the society of relying on scientific and technological innovation, $\mathrm{R} \& \mathrm{D}$ investment management is the most important thing for companies to improve their competitiveness especially true for artificial intelligence companies, which greatly affect corporate performance and corporate value. Therefore, we need to use the positive impact [10] of R \& D investment financial flexibility rational and make full use of its advantage in strategy formulation.

\subsection{Increasing R \& D Investment at the National Level}

1) Improvement of Tax Incentives

As the main source of national revenue, taxation is an important part that must be taken into account in the production and operation of an enterprise. The increasing policy support from government for science and technology enterprises is conducive to promoting popular entrepreneurship and innovation, cultivating forces for creating new technologies, updating new forms of business and providing new supply to promote economic upgrading and transformation. The tax law stipulates that high-tech enterprises shall be levied corporate income tax at a reduced rate of $15 \%$; corporate R \& D expenses may enjoy a 50\% deduction of preferential policies for $\mathrm{R} \& \mathrm{D}$ expenses. In the future, we should further improve the taxation policy, use tax incentives to reduce innovation costs and support artificial intelligence company technology innovation.

2) Strengthening the Protection of Intellectual Property Rights

The importance of intellectual property as an intangible asset of a company is self-evident. At present, China's laws and regulations on intellectual property are still not perfect, the government should strengthen the overall coordination of intellectual property protection work and improve the legal and policy system to strengthen the construction of the judicial and law enforcement system and Law enforcement must be strict. Strengthen the establishment of a long-term mechanism for the protection of intellectual property rights, crack down on and reduce all forms of intellectual property infringement, encourage enterprises to increase their confidence in national science and technology protection work to safeguard their legitimate rights and interests and fully mobilize their enthusiasm. At the same time, in order to support the development of high-tech enterprises and create a good environment for R \& D and application of artificial intelligence, the government should also attach importance to the guidance of scientific and technological innovation and implement innovation-driven development strategies except for protection.

\subsection{Increasing R \& D Investment from the Perspective of Financial Flexibility of Artificial Intelligence Companies}

In addition to actively responding to relevant national policies, enterprises should consider more effective financial and operational methods in light of financial flexibility in order to increase R \& D investment. 
1) Low-Cost Financing

The flexibility of financing is reflected in the financing channels and methods. Enterprises should compare the feasibility of multiple financing options on the premise of considering the financing program's financial impact, financing possibility and financing cost. New capital will affect the capital structure of the company, sometimes short-term financing can relieve some of the company's payable payments, thus satisfying the company's need for long-term funds can effectively and continuously resolve the capital requirements and maximize the use of leverage effectiveness of debt. Therefore, the goal of reducing the cost of financing can be achieved through credit methods, equity financing, and the choice of appropriate funding opportunities.

2) Flexible Use of Funds

From the foregoing, it can be seen that increasing R \& D investment will help improve the $\mathrm{R} \& \mathrm{D}$ intensity of enterprises. Therefore, companies can adjust their investment methods flexibly in the use of funds and make full use of multiple sources of funds, capitalize on the rational allocation of capital and allocate resources reasonably to reduce the waste of capital. Such as renting and temporarily hiring a professor to save money. In this way, companies can retain a considerable part of their funds to increase R \& D investment and they can also realize the normal operation of the rest of the work.

3) Fair Distribution of Income

Taking the dispersion of equity into consideration, financial flexibility can be fully used in the distribution of capital income. The higher the degree of ownership concentration, the more financial flexibility will be reserved and the distribution of cash dividends will be reduced. Enterprises must consider various influencing factors and take the interest requirements of stakeholders and balance the interests of investors into account, such as adopting the partner system and the equity incentive mechanism dividends without losing control.

\subsection{Strengthen Multiparty Cooperation to Achieve Mutual Benefit and Win-Win}

Enterprises may consider cooperating with other investors and innovating cooperation models to achieve mutual benefit and win-win results. For example, establish long-term cooperative relationships with universities, foreign companies, commercial banks and governments. On the one hand, the increase in government financial support can provide sufficient funds as a guarantee and encourage and encourage various artificial intelligence companies to increase $\mathrm{R} \&$ $\mathrm{D}$ investment; on the other hand, it can also reduce $\mathrm{R} \& \mathrm{D}$ difficulties through resource sharing and achieve lower R \& D investment and the goal of creating large $\mathrm{R}$ $\& D$ value. Take the advantages of combining "production, study and research" and with the help of technical support from the company's good platform and resources, universities and research institutes, we can promote multi-party cooperation and promote the overall development of enterprises and the industry. 


\subsection{Increase Propaganda and Establish Corporate Image}

Faced with the pressure of industry competition brought about by the influx of competitors in the industry, the importance of corporate communications has become increasingly prominent. As the main channel for shaping the external image of the enterprise and establishing the corporate brand, the strengthening of propaganda helps to increase the popularity and gain the support of many parties and the trust of customers. At the same time, a good corporate image can capture market share and occupy a larger market space. Therefore, a reasonable allocation of funds and appropriately increased investment in propaganda work will help build a good image of the company and create a virtuous circle.

\section{Fund Project}

1) 2017 Hohai University Business School "Education Department Teaching Reform Project": Training and Training of Undergraduate Academic Competence (writing and publishing academic papers).

2) 2018 Hohai University national undergraduate innovation and entrepreneurship training program project: Analysis on the complex relationship between R \& D investment and innovation performance of AI companies.

\section{Conflicts of Interest}

The authors declare no conflicts of interest regarding the publication of this paper.

\section{References}

[1] Zhu, Y., Chen, H.H., Tian, S.Y., et al. (2016) Artificial Intelligence: From Scientific Dream to New Blue Ocean-Analysis and Countermeasures of Artificial Intelligence Industry Development. Science and Technology Progress, 33, 66-70.

[2] Liu, C. and Wang, S.N (2016) "Unicorn" Phenomenon in New Economy. Chinese Economic Report, No. 6, 75-77.

[3] Chen, J. and Pan, H.Y. (2017) Cash Holding, Capital Structure and Corporate Value. Finance and Accounting Monthly, No. 15, 3-8.

[4] Prasad, A.S. (1982) Clinical and Biochemical Spectrum of Zinc Deficiency in Human Subjects. In: Prasad, A.S., Ed., Clinical, Biochemical and Nutritional Aspects of Trace Elements, Alan R. Liss Inc., New York, 5-15.

[5] Yang, Y., Wang, P., Li, Y.H. and Yang, D.Z. (2015) Research on the Impact of Fiscal Subsidy on Firm R \& D Investment and Performance: Empirical Evidence from Chinese GEM Listed Companies. Financial and Economic Review, No. 1, 24-31.

[6] Du, X.R., Chen, J. and Xie, X. (2017) Study on the Impact of Commercial Credit on the Growth of Firms: Based on the Thinking of Listed Companies in Small and Medium-sized Enterprises. Journal of Chongqing University of Technology, No. 5, 174-179

[7] Yin, Q.Y. and Hu, J.X. (2016) Financial Flexibility, Free Cash Flow, and Underinvestment: Empirical Evidence from Chinese Listed Companies. Journal of Hohai University, 18, 49-57.

[8] Li, J.J. (2014) Study on Debt Source Structure and Cash Holding Level of SMEs. 
China Economic \& Trade Review, No. 2.

[9] Deng, M.R. (2004) Research on the Theory and Method of Enterprise Financial System Flexibility. Wuhan Publishing House, Wuhan, 1-86.

[10] Allen, J.W. (1998) Capital Markets and Corporate Structure: the Equity Carve-Outs of Thermo Electron. Journal of Financial Economics, 48, 99-124. https://doi.org/10.1016/S0304-405X(98)00005-1 